\title{
STUDI INVESTIGASI ANTROPOMETRI NELAYAN DUSUN ERIE DAN DUSUN SERI, KECAMATAN NUSANIWE, KOTA AMBON
}

\author{
Ariviana Lientje Kakerissa* \\ Program Studi Teknik Industri, Universitas Pattimura, Kota Ambon, Indonesia \\ *E-mail korespondensi: ariviana.kakerissa@,fatek.unpatti.ac.id
}

\begin{abstract}
ABSTRAK
Penelitian ini bertujuan untuk menemukan model ukuran dimensi tubuh nelayan di dusun Erie dan Serie, Kecamatan Nusaniwe, Kota Ambon guna pengembangan perancangan alat bantu tangkap dan fasilitas penagkapan lainnya.Data antropometri yang dihasilkan dapat digunakan sebagai referensi bagi pengembangan alat tangkap dan fasilitas penangkapan lainnya bagi nelayan di kedua dusun tersebut dan juga bagi nelayan di wilayah lain di Maluku, serta dapat juga digunakan untuk mendesain kebutuhan peralatan bantu bagi masyarakat pesisir pada umumnya. Hasil penelitian ini adalah adanya data antropometri nelayan sebanyak 36 dimensi tubuh nelayan yang dapat digunakan sebagai acuan dalam perancangan produk bagi nelayan karena penelitian ini juga menghasilkan persentil ukuran yang dapat dipakai sebagai acuan untuk kategori ukuran sebuah desain, yakni persentil 5\%, 50\% dan 95\%. Dengan demikian, jika akan mendesaian peralatan tangkap dan fasilitas perikanan lainnya yang termasuk kategori ruang haruslah menggunakan ukuran dimensi pada persentil 95\%, sedangkan pada kategori jangkau harus menggunakan ukuran dimensi pada persentil 5\%.
\end{abstract}

Kata Kunci: antropometri, nelayan.

\begin{abstract}
This study aims to find a model for the dimensions of the fishermen's body dimensions in Erie and Serie Village, Nusaniwe District, Ambon City to develop the design of fishing aids and other catching facilities. The resulting anthropometric data can be used as a reference for the development of fishing gear and other fishing facilities for fishermen. in these two hamlets as well as for fishermen in other areas in Maluku, and can also be used to design the need for assistive equipment for coastal communities in general. The results of this study are the presence of fishermen's anthropometric data as many as 36 dimensions of the fishermen's body that can be used as a reference in product design for fishermen because this study also produces a size percentile that can be used as a reference for the size category of a design, namely the $5 \%, 50 \%$ and 95th percentiles. \%. Thus, if you are going to design fishing gear and other fishery facilities that are included in the space category, you must use the dimensions at the $95 \%$ percentile, while those in the reach category must use the dimensions at the $5 \%$ percentile.
\end{abstract}

Keywords: anthropometry, fishermen

\section{PENDAHULUAN}

Rata-rata masyarakat Maluku bermukim di wilayah pesisir dan berprofesi sebagai nelayan. Di Kecamatan Nusaniwe, Kota Ambon, terutama di Dusun Erie dan Seri, sebagian besar masyarakatnya berprofesi sebagai nelayan. Alat bantu tangkap dan fasilitas penangkapan ikan yang digunakan para nelayan adalah peralatan sederhana dan bersifat tradisional yang didesain tanpa menggunakan ukuran-ukuran yang valid sesuai karakteristik tubuh penggunanya dan hanya 
berdasarkan perasaan atau perkiraan perancang saja dan menimbulkan beberapa keluhan bagi nelayan.

Berdasarkan penelitian pendahuluan yang telah dilakukan melalui observasi langsung di lapangan tentang aktivitas nelayan dan melalui wawancara dengan beberapa nelayan, terdapat beberapa keluhan antara lain: sakit pada lengan, bahu, punggung dan pinggang karena beban berat pada jaring. Selain itu, ada juga keluhan dan kendala lainnya pada fasilitas area kapal yang tidak nyaman, karena tidak sesuai dengan ukuran tubuh nelayan. Keluhan ini dapat berimbas pada menurunnya produktivitas nelayan dan dapat menyebabkan resiko pada keselamatan dan kecelakaan kerja, seperti terpleset di deck kapal, jatuh saat pengoperasian alat tangkap ikan dan tenggelamnya kapal karena kelebihan muatan atau kesalahan saat olah gerak kapal. Semua peralatan dan fasilitas penangkapan yang saat ini digunakan dibuat secara umum tanpa mempertimbangkan karakteristik dan ukuran tubuh nelayan. Padahal semestinya setiap peralatan maupun fasilitas yang digunakan harus mempertimbangkan aspek ergonomis pemakai. Rancangan produk, peralatan kerja dan stasiun kerja harus sesuai dengan dimensi tubuh manusia sebagai pengguna. Ketidaksesuaian hasil rancangan dengan dimensi tubuh manusia akan berdampak pada ketidaknyaman dalam menggunakan rancangan tersebut sehingga akan menimbulkan kelelahan dini dan stres kerja. Jika hal ini berlangsung cukup lama akan menimbulkan kesalahan dalam melaksanakan kerja dan dampak yang lebih buruk lagi terjadinya kecelakaan kerja (Purnomo, 2013). Upaya yang dapat dilakukan salah satunya berupa penyesuaian ukuran tempat kerja dengan dimensi tubuh agar sesuai dengan kebutuhan tubuh manusia. Sebagian orang berpendapat bahwa kenyamanan kerja juga berpengaruh pada keselamatan kerja. Oleh karena itu, kenyamanan kerja selayaknya menjadi prioritas utama dalam rangka meningkatkan keselamatan kerja, khususnya pada kapal penangkapan ikan yang aktivitasnya berisiko tinggi.

Ukuran yang digunakan sebagai acuan sebuah desain stasiun kerja adalah ukuran dimensi tubuh masyarakat pada umumnya, tanpa memperhatikan karakteristik khusus masyarakat tertentu. Data antropometri masyarakat Indonesia sendiri belum ada yang benar-benar valid untuk dijadikan sebagai referensi bagi sebuah desain. Perbedaan suku, budaya dan ras di antara masyarakat di Indonesia cukup mempengaruhi ukuran dimensi tubuh.

Antropometri berasal dari "anthro" yang memiliki arti manusia dan "metri" yang memiliki arti ukuran. Menurut (Wignjosoebroto, 2008), antropometri adalah studi yang berkaitan dengan pengukuran dimensi tubuh manusia. Bidang antropometri meliputi berbagai ukuran tubuh manusia seperti berat badan, posisi ketika berdiri, ketika merentangkan tangan, lingkar tubuh, panjang tungkai, dan sebagainya.

Data antropometri digunakan untuk berbagai keperluan, seperti perancangan stasiun kerja, fasilitas kerja, dan desain produk agar diperoleh ukuran-ukuran yang sesuai dan layak dengan dimensi anggota tubuh manusia yang akan menggunakannnya.

Manusia memiliki berbagai ukuran tubuh manusia yang berbeda antara manusia yang satu dengan lainnya, seperti berat badan, ukuran tinggi tubuh ketika posisi berdiri, lingkar tubuh, serta posisi ketika merentangkan tangan, panjang tungkai, dan sebagainya. Data antropometri tersebut digunakan untuk berbagai keperluan, seperti perancangan stasiun kerja, fasilitas kerja, dan desain produk agar diperoleh ukuran-ukuran yang sesuai dan layak dengan dimensi anggota tubuh manusia yang akan menggunakannnya.

Dengan tersedianya data antropometri tubuh manusia Indonesia, maka kita dapat mengetahui ukuran yang presisi dan akurat sesuai dengan ukuran dimensi tubuh manusia Indonesia, seperti ketika kita akan merancang stasiun kerja dan mendesain produk. Kita dapat mengetahui jarak yang sesuai dan ergonomis ketika terdapat interaksi antara operator dengan kursi, meja dan seperangkat komputer. Kita juga dapat mengetahui desain yang tepat dan ergonomis ketika membuat sebuah produk seperti kursi, meja, jok mobil, dan baju.

Sebagian besar data antropometri dinyatakan dalam bentuk persentil. Suatu populasi untuk kepentingan studi dibagi dalam seratus kategori prosentase, dimana nilai tersebut akan diurutkan dari terkecil hingga terbesar pada suatu ukuran tubuh tertentu. 
Persentil menunjukkan suatu nilai prosentase tertentu dari orang yang memiliki ukuran pada atau di bawah nilai tersebut (Wignjosoebroto, 2008). Apabila dalam mendesain produk terdapat variasi untuk ukuran sebenarnya, maka seharusnya dapat merancang produk yang memiliki fleksibilitas dan sifat mampu menyesuaikan (adjustable) dengan suatu rentang tertentu (Wignjosoebroto, 2008). Oleh karena itu, untuk penetapan antropometri dapat menerapkan distribusi normal. Dalam statistik, distribusi normal dapat diformulasikan berdasarkan nilai ratarata dan standar deviasi dari data yang ada dan digabungkan dengan nilai persentil yang telah ada.

Penelitian ini dilakukan untuk menemukan model ukuran dimensi tubuh masyarakat nelayan di kota Ambon. Penelitian ini juga dimaksudkan untuk menemukan data antropometri masyarakat nelayan di kota Ambon pada khususnya dan Maluku pada umumnya yang nantinya dapat digunakan sebagai referensi dalam mendesain alat bantu penangkapan serta fasilitas-fasilitas penangkapan lainnya yang sesuai dengan karakteristik dimensi tubuh nelayan di Maluku.

\section{BAHAN DAN METODE}

Alat-alat yang digunakan dalam pengukuran Antropometri adalah sebagai berikut: antropometer, campbell caliper 20, kursi antropometri, pita meteran, segmometer, dan timbangan. Ada sebanyak 36 dimensi antropometri tubuh yang dapat diukur, dapat dilihat pada tabel berikut ini.

Tabel 1. Dimensi Antropometri Tubuh

\begin{tabular}{|c|c|c|c|}
\hline $\begin{array}{c}\text { Lambang } \\
\text { Dimensi } \\
\text { Tubuh }\end{array}$ & Nama Dimensi & $\begin{array}{c}\text { Lambang } \\
\text { Dimensi } \\
\text { Tubuh }\end{array}$ & Nama Dimensi \\
\hline D1 & Tinggi tubuh & D19 & Lebar pinggul \\
\hline D2 & Tinggi mata & D20 & Tebal dada \\
\hline D3 & Tinggi bahu & D21 & Tebal perut \\
\hline D4 & Tinggi siku & D22 & Panjang lengan atas \\
\hline D5 & Tinggi pinggul & $\mathrm{D} 23$ & Panjang lengan bawah \\
\hline D6 & Tinggi tulang ruas & D24 & Panjang rentang tangan ke depan \\
\hline D7 & Tinggi ujung jari & D25 & $\begin{array}{l}\text { Panjang bahu-genggaman tangan ke } \\
\text { depan }\end{array}$ \\
\hline D8 & Tinggi dalam posisi duduk & D26 & Panjang kepala \\
\hline D9 & Tinggi mata dalam posisi duduk & D27 & Lebar kepala \\
\hline D10 & Tinggi bahu dalam posisi duduk & D28 & Panjang tangan \\
\hline D11 & Tinggi siku dalam posisi duduk & D29 & Lebar tangan \\
\hline D12 & Tebal paha & D30 & Panjang kaki \\
\hline D13 & Panjang lutut & D31 & Lebar kaki \\
\hline D14 & Panjang popliteal & D32 & Panjang rentangan tangan ke samping \\
\hline D15 & Tinggi lutut & D33 & Panjang rentangan siku \\
\hline D16 & Tinggi popliteal & D34 & $\begin{array}{l}\text { Tinggi genggaman tangan ke atas } \\
\text { dalam posisi berdiri }\end{array}$ \\
\hline D17 & Lebar sisi bahu & D35 & $\begin{array}{l}\text { Tinggi genggaman ke atas dalam } \\
\text { posisi duduk }\end{array}$ \\
\hline D18 & Lebar bahu bagian atas & D36 & Panjang genggaman tangan ke depan \\
\hline
\end{tabular}

Pada penelitian ini dilakukan pengukuran dimensi tubuh nelayan dengan berpedoman pada 36 Dimensi Antropometri (lambang D1 - D36) yang telah ditetapkan oleh Antropometri Indonesia. Pengukuran antropometri tubuh nelayan dilakukan menggunakan atas-alat pengukuran yang telah disebutkan di atas. Jumlah nelayan yang dijadikan sampel dan diukur dimensi tubuhnya adalah sebanyak 60 orang nelayan di dusun Erie dan 60 orang nelayan di dusun Seri, kecamatan Nusaniwe, kota Ambon.

\section{HASIL DAN PEMBAHASAN}

a. Nilai Rata-rata Data Antropometri

Berdasarkan hasil pengukuran dimensi tubuh nelayan yang telah diukur pada saat penelitian ini, maka nilai rata-rata antropometri dimensi tubuh nelayan dusun Erie dan dusun Seri, kecamatan Nusaniwe, 
kota Ambon dapat dilihat pada Tabel 5.1. Dari tabel tersebut, ternyata ada perbedaan ukuran dimensi tubuh antara nelayan dusun Erie dan dusun Seri. Perbedaan yang sangat signifikan terdapat pada ukuran tinggi siku (D4) yaitu dengan selisih $18,66 \mathrm{~cm}$, tinggi pinggul (D5) $21,38 \mathrm{~cm}$, tinggi tulang ruas (D6) $24,58 \mathrm{~cm}$, lebar sisi bahu (D17) $21 \mathrm{~cm}$, panjang lengan atas (D22) 50,58 , panjang lengan bawah (D23) $11,84 \mathrm{~cm}$, panjang bahu-genggaman tangan ke depan(D24) $13,12 \mathrm{~cm}$, lebar kepala (D27) $23,30 \mathrm{~cm}$, panjang tangan (D28) 50,33cm, panjang genggaman tangan ke depan (D36) $25,83 \mathrm{~cm}$.

Perbedaan ukuran dimensi tubuh ini dapat disebabkan oleh berbagai faktor yang secara spesifik dapat diketahui melalui penelitian lebih lanjut. Namun hal terpenting yang dapat disimpulkan dari data ini adalah bahwa dalam perancangan alat tangkap dan fasilitas penangkapan lainnya, haruslah mempertimbangkan dimensi ukuran tersebut. Hal ini semata-mata hanya demi kenyamanan nelayan dalam melakukan aktivitasnya dan menghindari kecelakaan kerja.

Tabel 2. Nilai Rata-rata Data Antropometri Nelayan

\begin{tabular}{|c|c|c|c|}
\hline $\begin{array}{c}\text { Lambang } \\
\text { Dimensi Tubuh }\end{array}$ & Nama Dimensi & $\begin{array}{l}\text { Dusun Erie } \\
\qquad(\mathrm{Cm})\end{array}$ & $\begin{array}{l}\text { Dusun Seri } \\
(\mathrm{Cm})\end{array}$ \\
\hline D1 & Tinggi tubuh & 166,37 & 168,80 \\
\hline D2 & Tinggi mata & 157,18 & 150,96 \\
\hline D3 & Tinggi bahu & 136,28 & 130,98 \\
\hline D4 & Tinggi siku & 90,40 & 109,06 \\
\hline D5 & Tinggi pinggul & 84,43 & 105,81 \\
\hline D6 & Tinggi tulang ruas & 56,30 & 80,88 \\
\hline D7 & Tinggi ujung jari & 56,30 & 64,95 \\
\hline D8 & Tinggi dalam posisi duduk & 86,75 & 86,93 \\
\hline D9 & Tinggi mata dalam posisi duduk & 73,52 & 74,10 \\
\hline D10 & Tinggi bahu dalam posisi duduk & 57,47 & 55,00 \\
\hline D11 & Tinggi siku dalam posisi duduk & 23,67 & 28,13 \\
\hline D12 & Tebal paha & 48,36 & 47,05 \\
\hline D13 & Panjang lutut & 47,08 & 55,71 \\
\hline D14 & Panjang popliteal & 35,82 & 37,45 \\
\hline D15 & Tinggi lutut & 46,55 & 48,95 \\
\hline D16 & Tinggi popliteal & 36,55 & 36,43 \\
\hline D17 & Lebar sisi bahu & 42,83 & 63,83 \\
\hline D18 & Lebar bahu bagian atas & 34,25 & 42,80 \\
\hline D19 & Lebar pinggul & 42,23 & 43,76 \\
\hline $\mathrm{D} 20$ & Tebal dada & 20,96 & 31,43 \\
\hline $\mathrm{D} 21$ & Tebal perut & 23,08 & 28,30 \\
\hline D22 & Panjang lengan atas & 81,08 & 30,50 \\
\hline D23 & Panjang lengan bawah & 43,17 & 31,33 \\
\hline $\mathrm{D} 24$ & Panjang rentang tangan ke depan & 66,86 & 68,73 \\
\hline D25 & Panjang bahu- genggaman tangan ke depan & 58,86 & 71,98 \\
\hline D26 & Panjang kepala & 20,26 & 25,28 \\
\hline D27 & Lebar kepala & 15,60 & 38,90 \\
\hline $\mathrm{D} 28$ & Panjang tangan & 22,25 & 72,58 \\
\hline D29 & Lebar tangan & 9,55 & 13,90 \\
\hline D30 & Panjang kaki & 25,25 & 22,55 \\
\hline D31 & Lebar kaki & 12,38 & 7,55 \\
\hline D32 & Panjang rentangan tangan ke samping & 159,15 & 155,21 \\
\hline D33 & Panjang rentangan siku & 77,23 & 71,63 \\
\hline D34 & Tinggi genggaman tangan ke atas dalam posisi berdiri & 206,25 & 208,83 \\
\hline D35 & Tinggi genggaman ke atas dalam posisi duduk & 124,33 & 123,62 \\
\hline D36 & Panjang genggaman tangan ke depan & 58,50 & 84,33 \\
\hline
\end{tabular}

\section{b. Nilai Rata-rata Persentil Data Antropometri}

Sebagian besar data antropometri dinyatakan dalam bentuk persentil. Suatu populasi untuk kepentingan studi dibagi dalam seratus kategori prosentase, dimana nilai tersebut akan diurutkan dari terkecil hingga terbesar pada suatu ukuran tubuh tertentu. 
Persentil menunjukkan suatu nilai prosentase tertentu dari orang yang memiliki ukuran pada atau di bawah nilai tersebut (Wignjosoebroto, 2008). Apabila dalam mendesain produk terdapat variasi untuk ukuran sebenarnya, maka seharusnya dapat merancang produk yang memiliki fleksibilitas dan sifat mampu menyesuaikan (adjustable) dengan suatu rentang tertentu (Wignjosoebroto, 2008). Oleh karena itu, untuk penetapan antropometri dapat menerapkan distribusi normal. Dalam statistik, distribusi normal dapat diformulasikan berdasarkan nilai ratarata dan standar deviasi dari data yang ada dan digabungkan dengan nilai persentil yang telah ada. Perhitungan persentil dalam penilitian ini menggunakan software SPSS. Ukuran persentil yang digunakan pada penelitian ini adalah 5\% untuk ukuran persentil kecil, 50\% untuk ukuran persentil rata-rata dan $95 \%$ untuk ukuran persentil besar. Hasil perhitungan persentil dimensi tubuh nelayan untuk dusun Erie dan dusun Seri, kecamatan Nusaniwe, kota Ambon dapat dilihat pada tabel berikut.

Tabel 3. Nilai Rata-rata Persentil Data Antropometri Nelayan

\begin{tabular}{|c|c|c|c|c|c|c|c|}
\hline \multirow{2}{*}{$\begin{array}{c}\text { Lambang } \\
\text { Dimensi } \\
\text { Tubuh }\end{array}$} & \multirow[b]{2}{*}{ Nama Dimensi } & \multicolumn{3}{|c|}{ Dusun Erie } & \multicolumn{3}{|c|}{ Dusun Seri } \\
\hline & & $5 \%$ & $50 \%$ & $95 \%$ & $5 \%$ & $50 \%$ & $95 \%$ \\
\hline D1 & Tinggi tubuh & 161,05 & 166,00 & 171,00 & 163,00 & 167,00 & 170,00 \\
\hline $\mathrm{D} 2$ & Tinggi mata & 152,00 & 157,00 & 162,00 & 147,00 & 151,00 & 154,00 \\
\hline D3 & Tinggi bahu & 131,05 & 136,00 & 141,00 & 127,00 & 131,00 & 135,00 \\
\hline D4 & Tinggi siku & 100,05 & 105,00 & 110,00 & 105,00 & 109,00 & 113,00 \\
\hline D5 & Tinggi pinggul & 85,05 & 90,00 & 95,95 & 102,00 & 106,00 & 109,00 \\
\hline D6 & Tinggi tulang ruas & 81,05 & 85,50 & 91,00 & 77,00 & 81,00 & 84,00 \\
\hline D7 & Tinggi ujung jari & 52,00 & 55,00 & 61,00 & 61,00 & 65,00 & 68,95 \\
\hline D8 & Tinggi dalam posisi duduk & 83,00 & 85,50 & 92,00 & 83,00 & 85,00 & 92,00 \\
\hline D9 & Tinggi mata dalam posisi duduk & 70,00 & 73,00 & 75,95 & 71,00 & 72,00 & 78,00 \\
\hline D10 & Tinggi bahu dalam posisi duduk & 54,00 & 57,00 & 61,00 & 26,00 & 59,00 & 61,00 \\
\hline D11 & Tinggi siku dalam posisi duduk & 21,00 & 23,00 & 27,00 & 23,00 & 25,00 & 57,00 \\
\hline D12 & Tebal paha & 42,00 & 48,00 & 56,00 & 45,00 & 46,00 & 58,00 \\
\hline D13 & Panjang lutut & 43,00 & 47,00 & 50,00 & 52,00 & 55,00 & 59,00 \\
\hline D14 & Panjang popliteal & 31,00 & 35,00 & 42,00 & 32,00 & 36,00 & 42,95 \\
\hline D15 & Tinggi lutut & 43,00 & 47,00 & 51,00 & 42,00 & 48,00 & 51,00 \\
\hline D16 & Tinggi popliteal & 33,00 & 37,00 & 41,00 & 33,00 & 37,00 & 40,95 \\
\hline D17 & Lebar sisi bahu & 35,05 & 42,50 & 48,00 & 45,80 & 64,00 & 68,00 \\
\hline D18 & Lebar bahu bagian atas & 32,00 & 34,00 & 37,00 & 39,00 & 43,00 & 46,00 \\
\hline D19 & Lebar pinggul & 40,00 & 41,50 & 46,00 & 40,00 & 45,00 & 47,95 \\
\hline $\mathrm{D} 20$ & Tebal dada & 17,00 & 22,00 & 24,00 & 22,00 & 31,00 & 42,00 \\
\hline $\mathrm{D} 21$ & Tebal perut & 18,00 & 23,00 & 29,00 & 20,05 & 28,00 & 32,95 \\
\hline D22 & Panjang lengan atas & 48,00 & 51,00 & 54,95 & 27,00 & 31,00 & 34,00 \\
\hline D23 & Panjang lengan bawah & 40,00 & 42,00 & 47,00 & 28,00 & 32,00 & 34,00 \\
\hline D24 & Panjang rentang tangan ke depan & 63,00 & 67,00 & 69,00 & 66,00 & 68,00 & 71,00 \\
\hline $\mathrm{D} 25$ & Panjang bahu-genggaman tangan ke depan & 55,00 & 59,00 & 61,00 & 65,00 & 71,00 & 82,00 \\
\hline D26 & Panjang kepala & 17,00 & 20,00 & 23,00 & 21,00 & 25.00 & 45,60 \\
\hline $\mathrm{D} 27$ & Lebar kepala & 14,00 & 16,00 & 17,00 & 19,00 & 56,00 & 56,00 \\
\hline $\mathrm{D} 28$ & Panjang tangan & 20,00 & 23,00 & 24,00 & 56,75 & 71,00 & 76,00 \\
\hline D29 & Lebar tangan & 9,00 & 9,00 & 11,00 & 11,00 & 12,00 & 12,00 \\
\hline $\mathrm{D} 30$ & Panjang kaki & 24,00 & 24,00 & 29,95 & 20,00 & 22,00 & 25,95 \\
\hline D31 & Lebar kaki & 11,00 & 12,00 & 14,00 & 6,00 & 7,50 & 9,00 \\
\hline $\mathrm{D} 32$ & Panjang rentangan tangan ke samping & 154,00 & 160.00 & 163,00 & 143,35 & 155,00 & 167,00 \\
\hline D33 & Panjang rentangan siku & 76,00 & 76,00 & 81,99 & 67,00 & 71,00 & 78,00 \\
\hline D34 & $\begin{array}{l}\text { Tinggi genggaman tangan ke atas dalam } \\
\text { posisi berdiri }\end{array}$ & 201,05 & 205,50 & 211,00 & 126,45 & 213,00 & 215,95 \\
\hline D35 & $\begin{array}{l}\text { Tinggi genggaman ke atas dalam posisi } \\
\text { duduk }\end{array}$ & 118,00 & 124,00 & 130,00 & 121,05 & 124,00 & 125,10 \\
\hline D36 & Panjang genggaman tangan ke depan & 51,15 & 59,00 & 61,00 & 74,00 & 77,00 & 78,00 \\
\hline
\end{tabular}

Tabel di atas memperlihatkan batasan ukuran dimensi tubuh yang dapat dijadikan sebagai acuan dalam mendesain peralatan tangkap dan fasilitas perikanan lainnya. Penggunaan persentil dalam perhitungan disesuaikan dengan kategorinya. Dimensi ruang menggunakan persentil besar sedangkan dimensi jangkauan menggunakan persentil kecil (Purnomo, 2013). Dengan demikian, 
jika akan mendesaian peralatan tangkap dan fasilitas perikanan lainnya yang termasuk kategori ruang haruslah menggunakan ukuran dimensi pada persentil 95\%, dengakan pada kategori jangkau harus menggunakan ukuran dimensi pada persentil 5\%.

\section{KESIMPULAN}

Berdasarkan temuan studi, hasil analisis, dan pemodelan, maka dapat disimpulkan bahwa model ukuran dimensi tubuh nelayan di dusun Erie dan dusun Seri, Kecamatan Nusaniwe, Kota Ambon memiliki perbedaan ukuran pada beberapa dimensi. Pada jangka panjang, model yang dihasilkan dengan persentilnya dapat digunakan sebagai referensi bagi pengembangan alat tangkap dan fasilitas penagkapan lainnya bagi nelayan di Kota Ambon khususnya, dan di Maluku pada umumnya.

Data antropometri masyarakat nelayan dapat juga digunakan untuk mendesain kebutuhan peralatan bantu bagi masyarakat pesisir pada umumnya, sehingga dapat dijadikan sebagai referensi bagi pengembangan peralatan dan stasiun kerja masyarakat pesisir di wilayah Maluku.

\section{DAFTAR PUSTAKA}

Anggraini, D. A., \& Bati, N. C. (2016). Analisa Postur Kerja Dengan Nordic Body Map \& Reba Pada Teknisi Painting Di PT. Jakarta Teknologi Utama Motor Pekanbaru. 7(1).

Basya Irham Fanani, Boesono Herry \& Hapsari Trisnani Dwi (2017), Aspek Ergonomi Pada Aktivitas Penangkapan Ikan Kapal Pancing Ulur Di Ppn Prigi Trenggalek, Jurnal Perikanan Tangkap : Indonesian Journal of Capture Fisheries Vol. 1 No. 02, Semarang.

Cahyadi R \& Suwandi A, (2017)., Perancangan Alat Bantu Penangkap Ikan (Fishing Deck Machinery) Untuk Peningkatan Produktifitas Nelayan., Prosiding Seminar Nasional dan Teknologi Fakultas Teknik Universitas Muhammadiyah, Jakarta.

Kroemer, K. H. E. (2001). Engineering Anthropometry. Dalam Karwoski, W. S. Marras. (Ed.), Occupational Ergonomics: Pterperinciples of Work design. USA: CRC Press.

Pulat, B. Mustafa. (1992), Fundamental of Industrial Ergonomics, AT\&T Network Systems, Oklahoma City Works and School of Industrial Engineering, University of Oklahoma.

Purnomo Hari (2013), Antropometri dan Aplikasinya, Edisi Pertama, Graha Ilmu, Yogyakarta.

Di Provinsi Sumatera Selatan, Jurnal Saintek Perikanan Vol. 6, No. 1, 2010, 8-21.

Tahapary Jacomina \& Amir Syamsul Marlin (2014), Kegiatan Penangkapan Ikan Di Pesisir Barat Selatan Pulau Kei Kecil, Kepulauan Kei, Maluku Tenggara, Jurnal Galang Tropika Vol. 3 No.3 , ISSN: 2302-4187, hal. 127-131.

Tarwaka, dkk, (2004). Ergonomi Untuk Keselamatan, Kesehatan Kerja dan Produktifitas. Penerbit Uniba Press, Surakarta.

Tarwaka, (2011). Ergonomi Industri Dasar-dasar Pengetahuan Ergonomi dan Aplikasi di Tempat Kerja. Surakarta : Harapan Press.

Weri Michael Natanael \& Sucahyo, (2017), Keterkaitan Alat Tangkap Ikan dengan Jenis Ikan yang didapatkan di Rawa Pening, Jurnal Bioedukasi Vol. 10 No. 2, Hal 35-43, UNS, Solo.

Wijaya, K. (2019). Identifikasi Risiko Ergonomi Dengan Metode Nordic Body Map Terhadap Pekerja Konveksi Sablon Baju. Seminar Dan Konferensi Nasional IDEC, 2-3.

Wijaya M. Angga, Haulian Siboro Benedikta Anna \& Purbasari Anissa (2016)., Analisa Perbandingan Antropometri Bentuk Tubuh Mahasiswa Pekerja Galangan Kapal Dan Mahasiswa Pekerja Elektronika, Jurnal Profisiensi Vol. 4 No. 2, halaman 108- 117, Batam.

Wignjosoebroto, Sritomo. (2008). Ergonomi, Studi Gerak dan Waktu. Guna Widya. Surabaya. 